\title{
Can I Ever Use a Tampon Again?
}

\author{
Margaret Thew* \\ Medical Director, Adolescent Medicine Medical College of Wisconsin, USA
}

Submission: November 17, 2020; Published: November 23, 2020

*Corresponding author: Margaret Thew, Medical Director, Adolescent Medicine Medical College of Wisconsin, USA

\section{Case Report}

Case of a $16 \mathrm{y} / \mathrm{o}$ female with the past medical history of Raynaud's syndrome presented to local urgent care following two days of worsening malaise, sore throat, abdominal pain, and vomiting. Her vomiting became black and grainy which prompted the urgent care provider to administer IV fluids and assess her urine. Urine analysis show 20-50 white blood cells concerning for a urinary tract infection. She was discharged home with a followup arranged with her primary care doctor's office the next day. On the morning of the presentation, she was seen at her primary care doctor's office and endorsed worsening abdominal pain, fever, hypotension, and significant lightheadedness. She had a repeat urine analysis which was again positive for white blood cells and now positive for nitrites. Her primary care physician administered a dose of intramuscular Ceftriaxone and transferred her to the emergency room. Upon transfer to the emergency room, it was noted that this young woman was on day 5 of her menstrual cycle and had a retained tampon in place for roughly 24 hours. Tampon was removed immediately. Her presentation was concerning for sepsis as she was tachycardic, hypotensive, brisk capillary refill, afebrile, and a blotchy rash. Blood cultures were obtained, and she was given 3 liters of normal saline (NS) to support her hypotensive state. Despite the 3 liters of NS, she remained hypotensive and required a continuous infusion of norepinephrine to improve her blood pressures. She was quickly admitted to the pediatric intensive care unit. Her intensive care course lasted 2 days with the resumption of blood pressures without further need for additional vasopressors. She required 2 doses of Lasix due to compromised respiratory status and required oxygen. Following the first 2 doses of Lasix, her chest x-ray demonstrated persistent fluid on both lungs and two additional doses of Lasix were required. She stepped down to the acute care floors to continue her convalescence and was slowly weaned from oxygen before discharge home to family.

Infectious disease was consulted, and she was diagnosed with toxic septic shock syndrome (TSS) given the rapid improvement of hypotension with intravenous fluids, rash, and removal of the retained tampon. This diagnosis was confirmed by a vaginal swab growing Staphylococcus aureus. She was originally given Ceftriaxone but was switched to cephalexin and clindamycin while inpatient. She was discharged home on oral cephalexin only and instructed to no longer use tampons for the next 6 months and to not keep retained for longer than 8 hours at a time when resuming tampon use.

This young woman returned septic 2 months later with malaise, body aches, fever, and abdominal pain. Given her history of prior TSS, her parents brought her directly to the emergency room and was quickly admitted to the pediatric intensive care unit with respiratory and cardiac symptoms. She was again having her menstrual cycle, but this time it lasted fifteen days and she began using a diva menstrual cup. Before presenting to the emergency room, she had her diva cup in place for more than twelve hours. She was again admitted to the pediatric intensive care unit. During this admission, she required five liters of NS and epinephrine infusion for twelve hours. She required intravenous antibiotics including clindamycin, Zosyn, and vancomycin. Urine obtained upon admission grew 15,000 CFU Staphylococcus aureus and mixed organisms consistent with skin flora. It was concluded the urine was contaminated by vaginal flora. Infectious disease was again consulted, and, upon presentation, it was determined secondary TSS and low suspicion for urosepsis. She defervesced over the next 3 days and was discharged home on Clindamycin for 14 days.

During this second admission, gynecology was consulted and recommended menstrual suppression. She was advised to no longer use tampons, diva cups, or any intravaginal items for menstrual control. She followed up with Adolescent Medicine three days later and endorsed vomiting and nausea due to oral Clindamycin. Following discussion with the infectious disease provider, she was switched to Cephalexin to complete her antibiotic course. This young woman again requested clarification on the future use of a tampon. 
Toxic shock syndrome (TSS) was first identified in 1978 but was not brought to public attention until 1980 [1]. TSS can occur from either Staphylococcus aureus or Streptococcus bacterium which can grow on the polyester foam and increase in vaginal $\mathrm{pH}$ associated with tampon use [2]. The criteria for TSS includes having six of the following symptoms. These symptoms are fever, diffuse macular rash, hypotension which responds well to fluid resuscitation, gastrointestinal symptoms, muscular-skeletal, renal, hepatic, hematologic, and disorientation or alterations in consciousness. All women have had menstrual cycles at the time of presentation and tampon use has been associated with most cases [3]. Little data supports the associate between TSS and menstrual diva cups although there have been independent case reports. Recurrence of TSS is even rarer. Diva menstrual cups are increasing in popularity given effectiveness and the smaller footprint for our environmentally conscientious generation. Menstrual cups are silicone or rubber which are not associated with micro-bacterial growth, yet the accumulation of blood and air in the cup creates a medium for bacterial growth and have been found to have a higher association of Staphylococcus aureus than tampons [2,4]. Practitioners must screen appropriately for the use of diva menstrual cups when considering TSS as the differential.

The timing of the resumption of intravaginal devices is not well studied. Most sources are hypothetical and do not recommend further use of retained intravaginal menstrual hygiene products given the serious nature of TSS. Circumstantial recommendations consider waiting several cycles, 6 months, or 1 year avoiding intravaginal menstrual products, but there is no confirmed study
$[3,5]$. Future studies on the resumptions of intravaginal menstrual products should be considered. One consideration would be to evaluate vaginal bacteria through the collection of swabs for the presence of Staphylococcus aureus or Streptococcus bacterium before the reintroduction of intravaginal menstrual products. Once the organisms have been eradicated from the vagina intravaginal products may be reintroduced. Little evidence exists that negative bacterial swabs would be enough to safely re-introduction intravaginal products without recurrent TSS. Additionally, if intravaginal products are resumed, a strong recommendation must be incorporated to limit intravaginal retainment to less than 6 hours, no overnight retention, and handwashing before placement.

\section{References}

1. Reingold AL, Hargrett NT, Shands KN, Dan BB, Schmid GP, et al. (1982) Toxic shock syndrome surveillance in the united states, 1980 to 1981. Ann Intern Med 96(6). 875-880.

2. Mitchell MA, Bisch S, Arntfield S, Hosseini-Moghaddam SM (2015) A confirmed case of toxic shock syndrome associated with the use of menstrual cup. Can J Infect Dis Med Microbiol 26(4): 218-220.

3. Tanner MH, Pierce BJ, Hake DC (1981) Toxic shock syndrome. West J Med 134: 477-484.

4. Nongoux L, Chiaruzzi M, Badiou C, Baude J, Tristan A, et al. (2018) Impact of currently marketed tampons and menstrual cups on Staphylococcus aureus growth and toxic shock syndrome toxin 1 production In Vitro. Application of Environmental Microbiology 84(12): e00351-18.

5. Todd JK (1988) Toxic Shock Syndrome. Clin Microbiol Rev 1(4): 432 446.

\section{Your next submission with Juniper Publishers will reach you the below assets}

- Quality Editorial service

- Swift Peer Review

- Reprints availability

- E-prints Service

- Manuscript Podcast for convenient understanding

- Global attainment for your research

- Manuscript accessibility in different formats

( Pdf, E-pub, Full Tsext, Audio)

- Unceasing customer service

Track the below URL for one-step submission https://juniperpublishers.com/online-submission.php 